\title{
Minimally invasive esophagectomy: current status and future direction
}

\author{
Kirsten Maas - Surya Biere - Donald Van der Peet • \\ Miguel Cuesta
}

Published online: 11 January 2012

(c) The Author(s) 2012. This article is published with open access at Springerlink.com

We read with interest the review article on minimally invasive esophagectomy for cancer published recently in Surgical Endoscopy [1]. After an extensive study of the literature about the subject in the last few years, the authors concluded that minimally invasive esophagectomy is at least comparable to open esophagectomy. We do agree with the comments and conclusions of the authors, but in the context of the search and the final comment, we would like make two remarks.

First, our paper, published by Scheepers et al. [2], is not included in your extended search of the literature. Despite the fact that our study was the second largest series of minimally invasive transhiatal esophagectomies for cancer $(n=50)$. The results of this study were promising: length of operating time was $300 \mathrm{~min}$, with $18 \%$ conversions and $500 \mathrm{ml}$ of blood loss. There were $42 \%$ early complications and $8 \%$ late complications. ICU stay was 1 day and hospital stay was 13 days, with one in-hospital mortality. The rate of respiratory complications was $18 \%$, and there was one chylothorax (2\%) and no anastomotic leakage.

Second, concerning the necessity of a randomized trial, the authors stated that "this would not be likely to come into fruition ..." but it has actually been done in our department early this year under the TIME trial name. The protocol for this randomized study was published in the $B M C$ Surgery journal and also has a recognized international registration [3]. In this trial, the traditional open transthoracic procedure (combining thoracotomy and laparotomy) was compared to the minimally invasive transthoracic procedure (right thoracoscopy in prone position and laparoscopy) in 115 patients. Currently we are analyzing the database in order to publish our promising data as soon as possible. As the authors emphasized, these data are needed to substantiate the current formation of opinion on esophageal surgery.

Open Access This article is distributed under the terms of the Creative Commons Attribution Noncommercial License which permits any noncommercial use, distribution, and reproduction in any medium, provided the original author(s) and source are credited.

\section{References}

1. Butler N, Collins S, Memon B, Memon MA (2011) Minimally invasive oesophagectomy: current status and future direction. Surg Endosc 25:2071-2083

2. Scheepers JJ, Veenhof AA, van der Peet DL, van Groeningen C, Mulder C, Meijer S, Cuesta MA (2008) Laparoscopic transhiatal resection for malignancies of the distal esophagus: Outcome of the first 50 resected patients. Surgery 143(2):278-285

3. Biere SS, Maas KW, Bonavina L, Garcia JR, van Berge Henegouwen MI, Rosman C, de Lange ES, Bonjer HJ, Cuesta MA, van der Peet DL (2011) Traditional invasive vs. minimally invasive esophagectomy: a multi-center, randomized trial (TIME-trial). BMC Surg 11(1):2
K. Maas $(\varangle) \cdot$ S. Biere $\cdot$ D. Van der Peet $\cdot$ M. Cuesta

Department of Surgery, VU Medical Center, Amsterdam,

The Netherlands

e-mail: k.maas@vumc.nl

$\mathrm{S}$. Biere

e-mail: s.biere@vumc.nl 